\title{
An Assessment of Students' Satisfaction in Higher Education
}

\author{
Margarida Figueiredo ${ }^{1}$ (D), Ana Fernandes ${ }^{2}$ (D) Jorge Ribeiro $^{3}$ (D), \\ José Neves $^{4,5(\mathbb{M})}$ (D), Almeida $\operatorname{Dias}^{5}$ (D), and Henrique Vicente ${ }^{4,6}$ (D) \\ ${ }^{1}$ Departamento de Química, Escola de Ciências e Tecnologia, \\ Centro de Investigação em Educação e Psicologia, \\ Universidade de Évora, Évora, Portugal \\ mtf@uevora.pt \\ ${ }^{2}$ Departamento de Química, Escola de Ciências e Tecnologia, \\ Universidade de Évora, Évora, Portugal \\ anavilafernandes@gmail.com \\ ${ }^{3}$ Instituto Politécnico de Viana do Castelo, Rua da Escola Industrial e Comercial \\ de Nun'Álvares, 4900-347 Viana Do Castelo, Portugal \\ jribeiro@estg.ipvc.pt \\ ${ }^{4}$ Centro Algoritmi, Universidade do Minho, Braga, Portugal \\ jneves@di.uminho.pt \\ 5 Instituto Politécnico de Saúde do Norte, CESPU, Gandra, Portugal \\ a.almeida.dias@gmail.com \\ ${ }^{6}$ Departamento de Química, Escola de Ciências e Tecnologia, \\ REQUIMTE/LAQV, Universidade de Évora, Évora, Portugal \\ hvicente@uevora.pt
}

\begin{abstract}
Student's Satisfaction (SS) with a particular subject may impact the learning process, being the figure of attentiveness of the utmost importance over time, and also a very difficult undertaking to accomplish. To go forward with such exercise, a workable methodology for problem solving had to be built and tested. It is based on a thermodynamic approach to Knowledge Representation and Reasoning, which is the ultimate goal of SS assessment when working on a particular topic.
\end{abstract}

Keywords: Students' Satisfaction - Thermodynamics - Entropy · Higher Education - General Chemistry - Knowledge Representation and Reasoning • Logic Programming · Artificial Neural Networks 